OPEN ACCESS

Edited by:

Hansen Wang,

University of Toronto, Canada

Reviewed by:

Kazunori Nakajima,

Keio University School of Medicine,

Japan

Lavinia Alberi,

University of Fribourg, Switzerland

Eric C. Olson,

SUNY Upstate Medical University,

USA

${ }^{*}$ Correspondence:

Gum Hwa Lee

gumhwalee@chosun.ac.kr

Received: 04 March 2016 Accepted: 27 April 2016

Published: 09 May 2016

Citation:

Lee GH and D'Arcangelo G (2016) New Insights into Reelin-Mediated

Signaling Pathways.

Front. Cell. Neurosci. 10:122.

doi: 10.3389/fncel.2016.00122

\section{New Insights into Reelin-Mediated Signaling Pathways}

\author{
Gum Hwa Lee ${ }^{1 *}$ and Gabriella D'Arcangelo \\ ${ }^{1}$ College of Pharmacy, Chosun University, Gwangju, South Korea, ${ }^{2}$ Department of Cell Biology and Neuroscience, Rutgers, \\ The State University of New Jersey, Piscataway, NJ, USA
}

Reelin, a multifunctional extracellular protein that is important for mammalian brain development and function, is secreted by different cell types in the prenatal or postnatal brain. The spatiotemporal regulation of Reelin expression and distribution during development relates to its multifaceted function in the brain. Prenatally Reelin controls neuronal radial migration and proper positioning in cortical layers, whereas postnatally Reelin promotes neuronal maturation, synaptic formation and plasticity. The molecular mechanisms underlying the distinct biological functions of Reelin during and after brain development involve unique and overlapping signaling pathways that are activated following Reelin binding to its cell surface receptors. Distinct Reelin ligand isoforms, such as the full-length protein or fragments generated by proteolytic cleavage differentially affect the activity of downstream signaling pathways. In this review, we discuss recent advances in our understanding of the signaling transduction pathways activated by Reelin that regulate different aspects of brain development and function. A core signaling machinery, including ApoER2/VLDLR receptors, Src/Fyn kinases, and the adaptor protein Dab1, participates in all known aspects of Reelin biology. However, distinct downstream mechanisms, such as the Crk/Rap1 pathway and cell adhesion molecules, play crucial roles in the control of neuronal migration, whereas the PI3K/Akt/mTOR pathway appears to be more important for dendrite and spine development. Finally, the NMDA receptor (NMDAR) and an unidentified receptor contribute to the activation of the MEK/Erk1/2 pathway leading to the upregulation of genes involved in synaptic plasticity and learning. This knowledge may provide new insight into neurodevelopmental or neurodegenerative disorders that are associated with Reelin dysfunction.

Keywords: brain development, neuronal migration, dendrites, synaptogenesis, signal transduction

\section{INTRODUCTION}

Reelin is an extracellular glycoprotein that controls diverse aspects of mammalian brain development and function (D'Arcangelo, 2014). The most prominent activity of Reelin is the control of neuronal migration and cellular layer formation in the developing brain. This is evident from anatomical studies of reeler mutant mice that lack Reelin expression (Lambert de Rouvroit and Goffinet, 1998). These mutants exhibit a neurological phenotype characterized by ataxia and a typical "reeling" gate. Anatomically, their brains exhibit widespread neuronal lamination defects due to the failure of radially-migrating neurons to reach their destination in the developing forebrain, and cerebellar hypoplasia, which is likely due to the failure of Purkinje 
cells to form a cellular layer (Goffinet, 1983; Miyata et al., 1997). Similar phenotypes are observed in human patients carrying REELIN homozygous mutations, resulting in lissencephaly with cerebellar hypoplasia (Hong et al., 2000).

In addition to controlling neuronal migration in the prenatal brain, Reelin plays important roles in the postnatal and adult brain, promoting the maturation of dendrites, synaptogenesis, synaptic transmission and plasticity, thus modulating the formation and function of synaptic circuits. This view is supported not only by animal studies involving heterozygous reeler mice, which model some behavioral dysfunction similar to schizophrenia (Costa et al., 2002), but also by recent human genetic studies identifying heterozygous REELIN mutations in lateral temporal epilepsy (Dazzo et al., 2015), and pointing to REELIN as a risk factor in autism (De Rubeis et al., 2014). Furthermore, accumulating evidence that Reelin signaling antagonizes the toxic effects of $\beta$-amyloid at the synapse, underscores the potential relevance of this "developmental" factor for neurodegenerative disorders (Durakoglugil et al., 2009; Krstic et al., 2012; Pujadas et al., 2014).

To foster a better understanding of the mechanisms of development and disease, in this review we focus on recent advances in our knowledge of the signaling transduction pathways that regulate the different biological activities of Reelin in the brain.

\section{REELIN EXPRESSION AND CLEAVAGE}

The spatiotemporal regulation of Reelin expression underlies its multifaceted roles in brain development. During the embryonic development of forebrain structures Cajal-Retzius cells secrete high levels of Reelin in the marginal zone, thus regulating neuronal migration and cellular layer formation (D'Arcangelo et al., 1995; Ogawa et al., 1995). These cells begin to die shortly after birth and disappear from the neocortex once neuronal migration is completed. In the hippocampus, however, residual Cajal-Retzius continue to secrete Reelin at early postnatal days, affecting aspects of development such as axonal or dendrite branching and maturation (Del Río et al., 1997; Niu et al., 2004;
Kupferman et al., 2014). As postnatal development continues, the expression of Reelin becomes predominantly localized to a subset of GABAergic interneurons that are positioned throughout cortical and hippocampal cell layers (Alcántara et al., 1998; Pesold et al., 1998). Albeit at reduced levels, these interneurons continue to express Reelin in the juvenile and adult forebrain. The significance of this late postnatal and adult pattern of expression is likely related to the modulation of synaptic activity and plasticity (Weeber et al., 2002; Beffert et al., 2005; Pujadas et al., 2010; Trotter et al., 2013).

The mouse full-length Reelin protein is approximately $385 \mathrm{kDa}$ and is $95.2 \%$ identical to the human protein (D'Arcangelo et al., 1995). The main body of the protein is composed of eight unique repeats $(\mathrm{R})$, each centered around an epidermal growth factor (EGF)-like cysteine pattern that is typical of extracellular proteins (Figure 1). At the $\mathrm{N}$ terminus there is a signal peptide and a small region of similarity with $\mathrm{F}$-spondin, whereas at the $\mathrm{C}$ terminus there is a small carboxy-terminal region (CTR) that is positively charged. The presence of the signal peptide indicated that Reelin is an extracellular protein. Indeed, it is readily detected in the culture medium of Reelin-expressing cells (D'Arcangelo et al., 1997). Secretion is essential for function, and mutations that interfere with secretion cause a reeler phenotype identical to that resulting from null mutations (D'Arcangelo et al., 1997; de Bergeyck et al., 1997). After secretion, full-length Reelin is cleaved by metalloproteases at two specific sites, generating three large fragments, an $\mathrm{N}$-terminal $(\mathrm{Nt}=\mathrm{N}-\mathrm{R} 2)$, a central $(\mathrm{C}=\mathrm{R} 3-\mathrm{R} 6)$, and a C-terminal ( $\mathrm{Ct}=\mathrm{R} 6-\mathrm{CTR})$ fragment (Figure 1). The $\mathrm{C}$ fragment alone is sufficient to activate intracellular signaling and to induce layer formation in cortical slice cultures (Jossin et al., 2004; Yasui et al., 2007). However, the full-length protein is more potent than the $\mathrm{C}$ fragment, presumably due to the presence of the Nt region, which promotes aggregation, and the CTR, which promotes proper folding (Utsunomiya-Tate et al., 2000; Kubo et al., 2002; Nakano et al., 2007; Kohno et al., 2015). Recent studies identified the cleavage sites that produce the three major Reelin

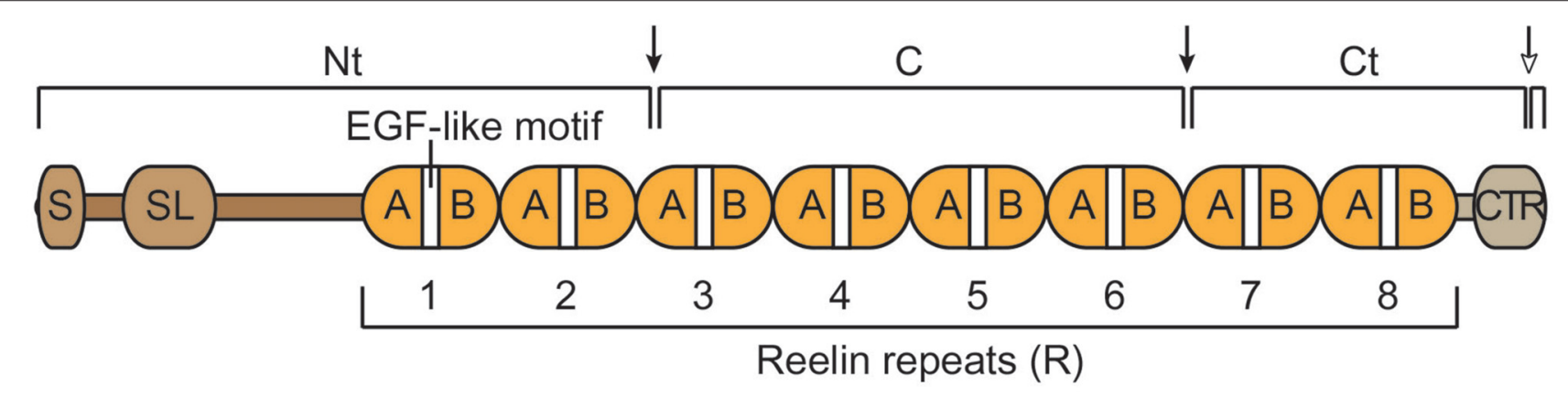

FIGURE 1 | Schematic structure of the Reelin protein and its cleavage fragments. Reelin contains a signal peptide (S), an F-spondin-like domain (SL), eight consecutive Reelin repeats (R) each harboring an epidermal growth factor (EGF)-like motif that separates two subdomains (A and B), and a positively charged carboxy-terminal region (CTR). The full-length protein is cleaved by extracellular metalloproteases at specific sites (arrows), an N-terminal (Nt) site within R3 and a C-terminal site between R6 and R7. These two cleavage events generate three large fragments, an N-terminal (Nt), a central (C) and a C terminal (Ct) fragment. An additional cleavage event (empty head arrow) occurs within the CTR (WC) and generates a small carboxy-terminal peptide. 
fragments (Koie et al., 2014; Sato et al., 2016) and demonstrated that the Nt cleavage affects the duration and the range of Reelin signaling activity in the developing cortex (Koie et al., 2014). Further studies are needed to identify proteases that carry out these processing events in vivo. In addition, recent studies further identified another cleavage site within the CTR (WC). Cleavage at this site releases a six amino acid carboxyterminal peptide, reducing signaling activity and hindering dendrite development in the postnatal neocortex (Kohno et al., 2015).

Taken together, the evidence so far indicates that Reelin processing downregulates the activity of the full-length protein; however cleavage events also produce diffusible fragments that potentially stimulate signaling activity away from the site of secretion (Jossin et al., 2007).

\section{REELIN RECEPTORS}

The best-characterized Reelin receptors are the apolipoprotein E receptor 2 (ApoER2, also called LRP8) and the very lowdensity lipoprotein receptor (VLDLR). These proteins belong to the low-density lipoprotein receptor (LDLR) family. They have partial functional redundancy and play an essential role in Reelin-mediated neuronal migration based on the observation that double knockout mice display a reeler-like phenotype (Trommsdorff et al., 1999). ApoER2 and VLDLR bind Reelin with high affinity and internalize the ligand in endocytic vesicles, leading to the activation of downstream signaling molecules (D’Arcangelo et al., 1999; Hiesberger et al., 1999; Strasser et al., 2004; Yasui et al., 2010). After the signal is transduced, some receptor molecules recycle to the membrane whereas others are targeted for lysosomal degradation (Hong et al., 2010). A Reelin domain contained within the $\mathrm{C}$ fragment and including the Lys 2467 residue is essential for ApoER2/VLDLR interaction, signal transduction and cortical layer formation (Jossin et al., 2004; Yasui et al., 2007). Despite functional overlap, ApoER2 and VLDLR play distinct roles in neuronal migration due, in part, to their different expression pattern. In the developing neocortex VLDLR is expressed almost exclusively in apical processes of migrating neurons at the top of the cortical plate where it mediates a mode of migration known as somal or terminal translocation, whereas ApoER2 is also expressed in the intermediate zone where it likely promotes the transition from multipolar to bipolar morphology and early stages of radial migration (Hirota et al., 2015). Other reported differences between the two receptors include their ability to internalize Reelin at different rate and in distinct lipid compartments, thus likely differentially affecting signal transduction machineries (Duit et al., 2010).

Other transmembrane proteins that have been proposed to function as Reelin receptors include $\beta 1$-containing integrins, which were first reported to bind Reelin in vitro (Dulabon et al., 2000). However, genetic knock out studies later demonstrated that $\beta 1$ integrins are required for radial glia scaffold formation rather than for neuronal migration per se (Belvindrah et al., 2007). Even though their function is not essential, possibly due to redundancy with other cell adhesion molecules, in utero electroporation studies suggest that $\beta 1$ integrins contribute to corticogenesis as downstream effectors. Reelin signaling was shown to alter integrin-dependent cell adhesion by downregulating $\alpha 3$ integrin levels in the cortical plate (Sanada et al., 2004), and by activating integrin $\alpha 5 \beta 1$, thus promoting the anchoring of leading processes to the fibronectinrich marginal zone (Sekine et al., 2012). It should be noted that in this model integrins do not bind Reelin directly and therefore do not function as receptors. Recently, another study suggested a direct interaction between Reelin and EphB tyrosine kinase receptors. The $\mathrm{Nt}$ region of Reelin was reported to bind EphB and activate forward signaling in neurons (Bouché et al., 2013). However, EphB-deficient mice display only a very mild migration phenotype, suggesting that they do not play a major role during prenatal brain development. Their involvement in postnatal functions of Reelin remains to be elucidated.

Taken together, genetic and biochemical data so far support the notion that ApoER2 and VLDLR are the major Reelin receptors in the developing brain.

\section{REELIN SIGNAL TRANSDUCTION IN THE CONTROL OF NEURONAL MIGRATION}

Disabled-1 (Dab1) is an intracellular adaptor protein that is essential for Reelin signal transduction. This protein binds the cytoplasmic tail of lipoprotein receptors, including ApoER2 and VLDLR (Trommsdorff et al., 1999) and upon Reelin binding, becomes phosphorylated on tyrosine residues by Srcfamily kinases (SFKs) Fyn and Src (Howell et al., 1999a; Figure 2A). These kinases are themselves upregulated in a Dab1dependent way via a positive feedback mechanism (Arnaud et al., 2003; Bock and Herz, 2003). Dab1 phosphorylation is required for neuronal migration, as demonstrated by the observation that phospho-mutant Dab1 mice (Howell et al., 2000), double Fyn/Src knockout mice (Kuo et al., 2005), as well as spontaneous or genetically engineered Dab1 knockout mice (Howell et al., 1997; Sheldon et al., 1997; Ware et al., 1997; Yoneshima et al., 1997; Kojima et al., 2000) all show similar reeler-like phenotypes. Dab1 signaling is rapidly downregulated by a mechanism that involves the ubiquitination of phosphoDab1 by the E3 ubiquitin ligase component Cullin 5, and its degradation by the proteasome system (Feng et al., 2007).

Genetic studies demonstrated that Dab1, and thus Reelin signaling, is specifically required for a specific mode of radial migration termed somal or terminal translocation, but not for glial-guided locomotion (Franco et al., 2011). The molecular mechanism of translocation involves the recruitment of Crk adaptor proteins, which bind phospho-Dab1 and cause the activation of the GTP exchange factor (GEF) C3G, and the subsequent activation of the Rap1 GTPase (Franco et al., 2011; Jossin and Cooper, 2011; Figure 2A). Consistently, double Crk/CrkL mutant mice display a reeler-like cortical phenotype (Park and Curran, 2008). The Crk/C3G/Rap1 pathway ultimately promotes the interaction between migrating neurons and Reelin- 


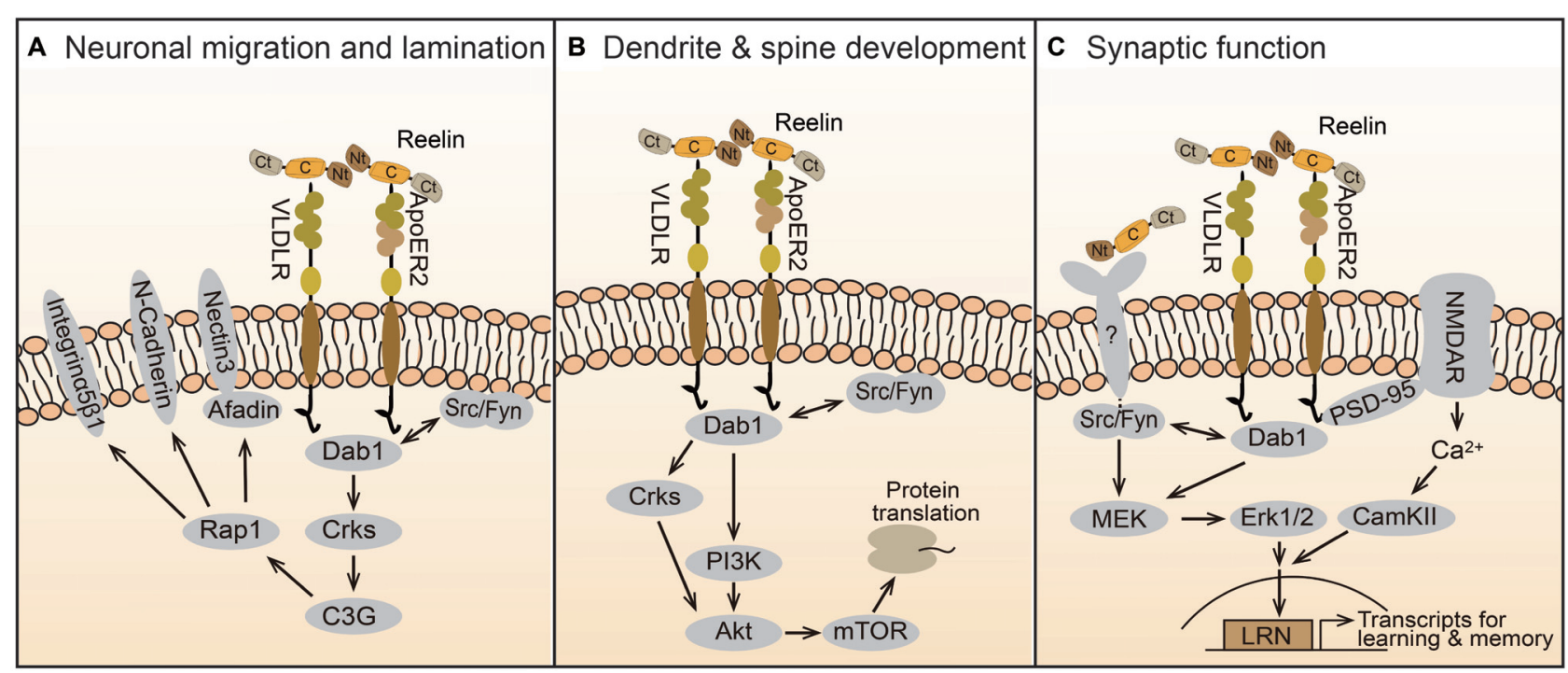

FIGURE 2 | Reelin signaling mechanisms in brain development and function. Reelin is secreted as a full-length protein that contains three large cleavable domains, an Nt, a C, and a Ct domain. The central domain binds to ApoER2 and VLDLR receptors, which internalize the ligand and transduce the Reelin signal by activating Src/Fyn kinases that phosphorylate the adaptor protein Dab1. Downstream of this canonical pathway, distinct signaling cascades regulate specific biologic activities at different times during brain development. (A) Prenatally, Reelin controls neuronal migration and cortical layer formation through the Crk/C3G/Rap1 pathway. This signaling cascade regulates the function of cell adhesion molecules, including nectin3, N-Cadherin, and Integrin $\alpha 5 \beta 1$, which facilitate somal translocation and cellular layer formation. (B) During early postnatal development, the Crk adaptor proteins and the PI3K-Akt-mTOR pathway contribute to Reelin activity by promoting protein translation, dendrite outgrowth and spine development. (C) In the late postnatal and adult brain Reelin affects synaptic function and plasticity. This activity is mediated in part by ApoER2, which interacts with the NMDAR through PSD-95, causing Ca ${ }^{2+}$ influx and the activation of CamKII. An unknown receptor also mediates the activation of the MEK-Erk1/2 pathway by Src/Fyn kinases. Together these signaling pathways promote synaptic activity and plasticity through the induction of immediate-early genes involved in learning and memory such as those containing LRN enhancers.

producing Cajal-Retzius cells through adhesion molecules such as nectins $1 / 3$ and $\mathrm{N}$-Cadherin, enabling neuronal translocation and inside-out layer formation (Gil-Sanz et al., 2013; Figure 2A). Given the enrichment of ApoER2 and VLDLR in the apical processes of migrating neurons near the marginal zone, both these receptors are likely to mediate the signal transduction that promotes translocation (Hirota et al., 2015). In addition, Reelin-Dab1 signaling through Rap1 and N-Cadherin affects the orientation of migrating neurons undergoing the transition from multipolar to bipolar morphology in the intermediate zone, before initiating radial migration into the cortical plate (Jossin and Cooper, 2011). This migration step may be mediated preferentially by ApoER2, since this is the only receptor that is expressed in the intermediate zone (Hirota et al., 2015).

In addition to Crks and Rap1, biochemical studies identified several molecules that may be involved in Reelin-dependent neuronal migration. These include proteins that regulate cytoskeletal dynamics and cell motility, such as Lis1, Nck $\beta$ and N-WASP (Assadi et al., 2003; Pramatarova et al., 2003; Suetsugu et al., 2004), and proteins that downregulate Rap1 due to their GTPase activating protein (GAP) activity. Among Dab1interacting proteins Lis1, the product of the PAFAH1b1 gene that is responsible for human lissencephaly type I, may be particularly relevant to cortical development. Lis1 binding to phosphoDab1 is Reelin-dependent, and genetic interaction between Dab1 and PAFAH1b1 demonstrates a functional relationship between these proteins (Assadi et al., 2003). Furthermore, Lis1interacting PAFAH1b alpha subunits bind specifically to VLDLR, potentially promoting the interaction between Lis1 and Dab1 downstream of this receptor (Zhang et al., 2007). Lis1 then affects cytoskeletal dynamics necessary for radial migration through the dynein motor complex (Wynshaw-Boris and Gambello, 2001). Additionally, Dab2IP, a Dab1-binding protein that functions as a Rap GAP, as well as Rap1GAP, were shown to affect neuronal migration in the neocortex (Franco et al., 2011; Jossin and Cooper, 2011; Lee et al., 2012; Qiao et al., 2013). Even though a direct involvement of Rap GAPs in Reelin signaling has not been established, it is likely that this class of proteins regulates Rap1 activity, balancing the GEF activity of C3G and thus enabling proper neuronal orientation and migration through the cortical plate.

\section{REELIN SIGNAL TRANSDUCTION IN THE CONTROL OF DENDRITE AND SPINE DEVELOPMENT}

Dendrite outgrowth is disrupted in homozygous reeler mice. Dendritic defects are also apparent in immature hippocampal or cortical cultures isolated from mutant mice, but not in mature cultures (Niu et al., 2004; Jossin and Goffinet, 2007; MacLaurin et al., 2007). Since Reelin treatment rescued these defects, these in vitro studies first demonstrated that Reelin directly promotes dendrite development. Following studies further demonstrated 
that Reelin enables initial dendritic outgrowth by promoting the extension of the Golgi apparatus into apical dendrites (Matsuki et al., 2010), and then orienting and stabilizing the leading processes in the marginal zone (Chai et al., 2015; Kohno et al., 2015; O’Dell et al., 2015). The signal transduction machinery that mediates the activity of Reelin on dendrite development involves the canonical pathway that also controls neuronal migration, including ApoER2/VLDLR, Dab1, SFKs and Crks (Niu et al., 2004; Park and Curran, 2008). Downstream of Dab1, the signaling mechanism that affects dendrite development likely involves the Phosphoinositide 3-kinase (PI3K) and Akt (Figure 2B). Earlier studies demonstrated that Reelin activates PI3K and Akt in vitro in a manner that is dependent on SFK activity and Dab1 phosphorylation (Beffert et al., 2002; Bock et al., 2003). PI3K may be activated through direct interaction between the regulatory subunit $\mathrm{p} 85 \alpha$ and Dab1 (Bock et al., 2003). Akt is likely activated, at least in part, by the classic PI3K/PDK cascade, however, in vivo studies demonstrated that the Crk adaptor proteins are required for Reelin-induced Akt phosphorylation, placing the kinase functionally downstream of these adaptors (Park and Curran, 2008). Downstream of Akt, mTOR and further downstream proteins such as p70S6K and ribosomal protein S6 are robustly induced by Reelin treatment in neuronal cultures and likely contribute to dendrite growth (Jossin and Goffinet, 2007; Ventruti et al., 2011; Figure 2B).

Other molecules that have been implicated in Reelindependent dendrite outgrowth include the amyloid precursor protein (APP; Hoe et al., 2009), which binds Dab1 via its cytoplasmic tail (Homayouni et al., 1999; Howell et al., 1999b), and the Cdc42/Racl guanine nucleotide exchange factor $\alpha$ PIX, which affects dendritic Golgi translocation (Meseke et al., 2013). In addition to outgrowth, dendrite compartmentalization is an important aspect of maturation that is affected by Reelin. In the hippocampus, distal apical dendrites of pyramidal neurons express specific ion channels. Recent studies demonstrated that Dab1/SFK signaling is required for the molecular identity of this dendritic compartment, which regulates the processing of information in hippocampal circuits (Kupferman et al., 2014). Reelin signaling also promotes dendritic spine formation and growth in the cortex and hippocampus of juvenile mice (Niu et al., 2008; Pujadas et al., 2010; Iafrati et al., 2014). The signaling mechanism that underlies this function involves the canonical pathway and possibly additional signaling molecules such as RasGRF1/CamMKII (DiBattista et al., 2015; Kim et al., 2015). Finally, the molecular composition of the dendritic spines is affected by Reelin. Specifically, Reelin promotes the maturation of spines by regulating the NMDA receptor (NMDAR) subunit composition via an unidentified mechanism (Groc et al., 2007; Ventruti et al., 2011).

\section{REELIN SIGNALING AND THE MODULATION OF SYNAPTIC FUNCTION}

Heterozygous reeler mice exhibit altered hippocampal synaptic plasticity and multiple behavioral abnormalities, such as defects in executive function and contextual fear conditioning learning (Brigman et al., 2006; Krueger et al., 2006; Qiu et al., 2006). Early culture studies demonstrated that Reelin potently enhances hippocampal long-term potentiation (LTP), a cellular mechanism underlying learning and memory, and this effect is dependent on the presence of both, VLDLR and ApoER2 (Weeber et al., 2002). A specific splicing variant of ApoER2 was required for Reelin-induced LTP enhancement and memory formation in vivo (Beffert et al., 2005). Mechanistically, it was shown that this ApoER2 variant interacts with the NMDAR through PSD-95, and this complex mediates Reelin-induced $\mathrm{Ca}^{++}$influx through the NMDAR (Beffert et al., 2005; Chen et al., 2005; Figure 2C). Genetic studies later demonstrated that Dab1 is also required for Reelin-induced enhancement of hippocampal LTP and for hippocampal-dependent behavioral tasks (Trotter et al., 2013). This study also demonstrated that postnatal Dab1 loss affects basal and plasticity-induced Erk1/2 signaling, suggesting a cross-talk with canonical Reelin signaling. Indeed, Reelin was shown to induce Erk1/2 signaling in a SFK-dependent manner in cultured neurons (Lee et al., 2014). Surprisingly, however, Reelin-induced Erk1/2 phosphorylation did not require the activity of ApoER2 and VLDLR, and it was only partially dependent on Dab1, suggesting the involvement of an unidentified receptor triggering a non-canonical pathway (Figure 2C). Erk1/2 activation leads to the expression of synaptic immediate-early genes (IEGs), and thus potentially affects synaptic function (Lee et al., 2014). Others further showed that Reelin induces IEGs expression via a novel enhancer element named LRN (LRP8-Reelin-Neuronal), and that these events affect associative learning. In this model, interaction between the ApoER2 (LRP8) and the NMDAR triggers $\mathrm{Ca}^{++}$influx, Erk1/2 signaling and CREB-dependent IEGs transcription (Telese et al., 2015). In addition, they reported that proteolytical cleavage of ApoER2 by $\gamma$-secretase is a crucial component of the synapse-to-nuclear signaling triggered by Reelin. Interestingly, Notch1, another $\gamma$-secretase substrate, was also recently shown to contribute to Reelin-mediated synaptic potentiation by interacting with ApoER2 and NMDAR, and stimulating Erk1/2 activity and CREB-dependent transcription (Brai et al., 2015).

In addition to its well-documented postsynaptic effects, Reelin also acts presynaptically, causing a rapid enhancement of spontaneous neurotransmitter release. This effect is due to the mobilization of VAMP7-containing synaptic vesicles, and requires canonical ApoER2/VLDLR receptors, PI3K and $\mathrm{Ca}^{++}$signaling (Hellwig et al., 2011; Bal et al., 2013). Despite robust pre- and postsynaptic effects, acute deletion of the Reelin gene in adult mice does not result in impaired synaptic plasticity. However, it renders the adult brain strikingly sensitive to amyloid-induced synaptic suppression, leading to profound learning disabilities (Lane-Donovan et al., 2015). Although specific molecular and physiological mechanisms remain to be further elucidated, these findings indicate that Reelin has the potential to modulate synaptic activity and thus affect memory formation in the adult and aging brain. 


\section{AUTHOR CONTRIBUTIONS}

GHL wrote the first draft of the manuscript and made the figures. GD wrote and revised the manuscript.

\section{REFERENCES}

Alcántara, S., Ruiz, M., D’Arcangelo, G., Ezan, F., de Lecea, L., Curran, T., et al. (1998). Regional and cellular patterns of Reelin mRNA expression in the forebrain of the developing and adult mouse. J. Neurosci. 18, 7779-7799.

Arnaud, L., Ballif, B. A., and Cooper, J. A. (2003). Regulation of protein tyrosine kinase signaling by substrate degradation during brain development. Mol. Cell. Biol. 23, 9293-9302. doi: 10.1128/mcb.23.24.9293-9302.2003

Assadi, A. H., Zhang, G., Beffert, U., McNeil, R. S., Renfro, A. L., Niu, S., et al. (2003). Interaction of reelin signaling and Lis1 in brain development. Nat. Genet. 35, 270-276. doi: 10.1038/ng1257

Bal, M., Leitz, J., Reese, A. L., Ramirez, D. M., Durakoglugil, M., Herz, J., et al. (2013). Reelin mobilizes a VAMP7-dependent synaptic vesicle pool and selectively augments spontaneous neurotransmission. Neuron 80, 934-946. doi: 10.1016/j.neuron.2013.08.024

Beffert, U., Morfini, G., Bock, H. H., Reyna, H., Brady, S. T., and Herz, J. (2002). Reelin-mediated signaling locally regulates protein kinase B/Akt and glycogen synthase kinase 3beta. J. Biol. Chem. 277, 49958-49964. doi: 10.1074/jbc. $\mathrm{m} 209205200$

Beffert, U., Weeber, E. J., Durudas, A., Qiu, S., Masiulis, I., Sweatt, J. D., et al. (2005). Modulation of synaptic plasticity and memory by Reelin involves differential splicing of the lipoprotein receptor ApoER2. Neuron 47, 567-579. doi: 10.1016/j.neuron.2005.07.007

Belvindrah, R., Graus-Porta, D., Goebbels, S., Nave, K. A., and Müller, U. (2007). Betal integrins in radial glia but not in migrating neurons are essential for the formation of cell layers in the cerebral cortex. J. Neurosci. 27, 13854-13865. doi: 10.1523/JNEUROSCI.4494-07.2007

Bock, H. H., and Herz, J. (2003). Reelin activates SRC family tyrosine kinases in neurons. Curr. Biol. 13, 18-26. doi: 10.1016/s0960-9822(02) 01403-3

Bock, H. H., Jossin, Y., Liu, P., Förster, E., May, P., Goffinet, A. M., et al. (2003). PI3-Kinase interacts with the adaptor protein Dab1 in response to Reelin signaling and is required for normal cortical lamination. J. Biol. Chem. 278, 38772-38779. doi: 10.1074/jbc.m306416200

Bouché, E., Romero-Ortega, M. I., Henkemeyer, M., Catchpole, T., Leemhuis, J., Frotscher, M., et al. (2013). Reelin induces EphB activation. Cell Res. 23, 473-490. doi: 10.1038/cr.2013.7

Brai, E., Marathe, S., Astori, S., Fredj, N. B., Perry, E., Lamy, C., et al. (2015). Notch1 regulates hippocampal plasticity through interaction with the reelin pathway, glutamatergic transmission and creb signaling. Front. Cell. Neurosci. 9:447. doi: $10.3389 /$ fncel.2015.00447

Brigman, J. L., Padukiewicz, K. E., Sutherland, M. L., and Rothblat, L. A. (2006). Executive functions in the heterozygous reeler mouse model of schizophrenia. Behav. Neurosci. 120, 984-988. doi: 10.1037/0735-7044. 120.4.984

Chai, X., Fan, L., Shao, H., Lu, X., Zhang, W., Li, J., et al. (2015). Reelin induces branching of neurons and radial glial cells during corticogenesis. Cereb. Cortex 25, 3640-3653. doi: 10.1093/cercor/bhu216

Chen, Y., Beffert, U., Ertunc, M., Tang, T. S., Kavalali, E. T., Bezprozvanny, I., et al. (2005). Reelin modulates NMDA receptor activity in cortical neurons. J. Neurosci. 25, 8209-8216. doi: 10.1523/JNEUROSCI.1951-05.2005

Costa, E., Chen, Y., Davis, J., Dong, E., Noh, J. S., Tremolizzo, L., et al. (2002). REELIN and schizophrenia: a disease at the interface of the genome and the epigenome. Mol. Interv. 2, 47-57. doi: 10.1124/mi.2.1.47

D'Arcangelo, G. (2014). Reelin in the years: controlling neuronal migration and maturation in the mammalian brain. Adv. Neurosci. 2014:19. doi: 10 . $1155 / 2014 / 597395$

D’Arcangelo, G., Homayouni, R., Keshvara, L., Rice, D. S., Sheldon, M., and Curran, T. (1999). Reelin is a ligand for lipoprotein receptors. Neuron 24, 471-479. doi: 10.1016/s0896-6273(00)80860-0

\section{ACKNOWLEDGMENTS}

This study was supported by a research fund from Chosun University (2015).

D’Arcangelo, G., Miao, G. G., Chen, S. C., Soares, H. D., Morgan, J. I., and Curran, T. (1995). A protein related to extracellular matrix proteins deleted in the mouse mutant reeler. Nature 374, 719-723. doi: 10.1038/374719a0

D’Arcangelo, G., Nakajima, K., Miyata, T., Ogawa, M., Mikoshiba, K., and Curran, T. (1997). Reelin is a secreted glycoprotein recognized by the CR-50 monoclonal antibody. J. Neurosci. 17, 23-31.

Dazzo, E., Fanciulli, M., Serioli, E., Minervini, G., Pulitano, P., Binelli, S., et al. (2015). Heterozygous reelin mutations cause autosomal-dominant lateral temporal epilepsy. Am. J. Hum. Genet. 96, 992-1000. doi: 10.1016/j.ajhg.2015. 04.020

de Bergeyck, V., Nakajima, K., Lambert de Rouvroit, C., Naerhuyzen, B., Goffinet, A. M., Miyata, T., et al. (1997). A truncated Reelin protein is produced but not secreted in the "Orleans" reeler mutation (Reln $\left.{ }^{r l-O r l}\right)$. Brain Res. Mol. Brain Res. 50, 85-90. doi: 10.1016/s0169-328x(97)00166-6

De Rubeis, S., He, X., Goldberg, A. P., Poultney, C. S., Samocha, K., Cicek, A. E., et al. (2014). Synaptic, transcriptional and chromatin genes disrupted in autism. Nature 515, 209-215. doi: 10.1038/nature13772

Del Río, J. A., Heimrich, B., Borrell, V., Förster, E., Drakew, A., Alcántara, S., et al. (1997). A role for Cajal-Retzius cells and reelin in the development of hippocampal connections. Nature 385, 70-74. doi: 10.1038/385070a0

DiBattista, A. M., Dumanis, S. B., Song, J. M., Bu, G., Weeber, E., Rebeck, G. W., et al. (2015). Very low density lipoprotein receptor regulates dendritic spine formation in a RasGRF1/CaMKII dependent manner. Biochim. Biophys. Acta 1853, 904-917. doi: 10.1016/j.bbamcr.2015.01.015

Duit, S., Mayer, H., Blake, S. M., Schneider, W. J., and Nimpf, J. (2010). Differential functions of ApoER2 and very low density lipoprotein receptor in Reelin signaling depend on differential sorting of the receptors. J. Biol. Chem. 285, 4896-4908. doi: 10.1074/jbc.M109.025973

Dulabon, L., Olson, E. C., Taglienti, M. G., Eisenhuth, S., McGrath, B., Walsh, C. A., et al. (2000). Reelin binds $\alpha 3 \beta 1$ integrin and inhibits neuronal migration. Neuron 27, 33-44. doi: 10.1016/s0896-6273(00)00007-6

Durakoglugil, M. S., Chen, Y., White, C. L., Kavalali, E. T., and Herz, J. (2009) Reelin signaling antagonizes beta-amyloid at the synapse. Proc. Natl. Acad. Sci. U S A 106, 15938-15943. doi: 10.1073/pnas.0908176106

Feng, L., Allen, N. S., Simo, S., and Cooper, J. A. (2007). Cullin 5 regulates Dab1 protein levels and neuron positioning during cortical development. Genes Dev. 21, 2717-2730. doi: 10.1101/gad.1604207

Franco, S. J., Martinez-Garay, I., Gil-Sanz, C., Harkins-Perry, S. R., and Müller, U. (2011). Reelin regulates cadherin function via Dab1/Rapl to control neuronal migration and lamination in the neocortex. Neuron 69, 482-497. doi: 10.1016/j. neuron.2011.01.003

Gil-Sanz, C., Franco, S. J., Martinez-Garay, I., Espinosa, A., Harkins-Perry, S., and Müller, U. (2013). Cajal-Retzius cells instruct neuronal migration by coincidence signaling between secreted and contact-dependent guidance cues. Neuron 79, 461-477. doi: 10.1016/j.neuron.2013.06.040

Goffinet, A. M. (1983). The embryonic development of the cerebellum in normal and reeler mutant mice. Anat. Embryol. 168, 73-86. doi: 10.1007/bf00305400

Groc, L., Choquet, D., Stephenson, F. A., Verrier, D., Manzoni, O. J., and Chavis, P. (2007). NMDA receptor surface trafficking and synaptic subunit composition are developmentally regulated by the extracellular matrix protein Reelin. J. Neurosci. 27, 10165-10175. doi: 10.1523/jneurosci.1772-07.2007

Hellwig, S., Hack, I., Kowalski, J., Brunne, B., Jarowyj, J., Unger, A., et al. (2011). Role for Reelin in neurotransmitter release. J. Neurosci. 31, 2352-2360. doi: 10. 1523/JNEUROSCI.3984-10.2011

Hiesberger, T., Trommsdorff, M., Howell, B. W., Goffinet, A. M., Mumby, M. C., Cooper, J. A., et al. (1999). Direct binding of Reelin to VLDL receptor and ApoE receptor 2 induces tyrosine phosphorylation of Disabled-1 and modulates Tau phosphorylation. Neuron 24, 481-489. doi: 10.1016/s0896-6273(00)80861-2

Hirota, Y., Kubo, K., Katayama, K., Honda, T., Fujino, T., Yamamoto, T. T., et al. (2015). Reelin receptors ApoER2 and VLDLR are expressed in distinct 
spatiotemporal patterns in developing mouse cerebral cortex. J. Comp. Neurol. 523, 463-478. doi: 10.1002/cne.23691

Hoe, H. S., Lee, K. J., Carney, R. S., Lee, J., Markova, A., Lee, J. Y., et al. (2009). Interaction of reelin with amyloid precursor protein promotes neurite outgrowth. J. Neurosci. 29, 7459-7473. doi: 10.1523/JNEUROSCI.4872-08.2009

Homayouni, R., Rice, D. S., Sheldon, M., and Curran, T. (1999). Disabled-1 binds to the cytoplasmic domain of amyloid precursor-like protein 1. J. Neurosci. 19, 7507-7515.

Hong, C., Duit, S., Jalonen, P., Out, R., Scheer, L., Sorrentino, V., et al. (2010). The E3 ubiquitin ligase IDOL induces the degradation of the low density lipoprotein receptor family members VLDLR and ApoER2. J. Biol. Chem. 285, 19720-19726. doi: 10.1074/jbc.M110.123729

Hong, S. E., Shugart, Y. Y., Huang, D. T., Shahwan, S. A., Grant, P. E., Hourihane, J. O., et al. (2000). Autosomal recessive lissencephaly with cerebellar hypoplasia is associated with human RELN mutations. Nat. Genet. 26, 93-96. doi: $10.1038 / 79246$

Howell, B. W., Gertler, F. B., and Cooper, J. A. (1997). Mouse disabled (mDab)1: a src binding protein implicated in neuronal development. EMBO J. 16, 121-132. doi: 10.1093/emboj/16.1.121

Howell, B. W., Herrick, T. M., and Cooper, J. A. (1999a). Reelin-induced tyrosine phosphorylation of Disabled 1 during neuronal positioning. Genes. Dev. 13, 643-648. doi: 10.1101/gad.13.6.643

Howell, B. W., Herrick, T. M., Hildebrand, J. D., Zhang, Y., and Cooper, J. A. (2000). Dab1 tyrosine phosphorylation sites relay positional signals during mouse brain development. Curr. Biol. 10, 877-885. doi: 10.1016/s09609822(00)00608-4

Howell, B. W., Lanier, L. M., Frank, R., Gertler, F. B., and Cooper, J. A. (1999b). The disabled 1 phosphotyrosine-binding domain binds to the internalization signals of transmembrane glycoproteins and to phospholipids. Mol. Cell. Biol. 19, 5179-5188. doi: 10.1128/mcb.19.7.5179

Iafrati, J., Orejarena, M. J., Lassalle, O., Bouamrane, L., Gonzalez-Campo, C., and Chavis, P. (2014). Reelin, an extracellular matrix protein linked to early onset psychiatric diseases, drives postnatal development of the prefrontal cortex via GluN2B-NMDARs and the mTOR pathway. Mol. Psychiatry 19, 417-426. doi: $10.1038 / \mathrm{mp} .2013 .66$

Jossin, Y., and Cooper, J. A. (2011). Reelin, Rap1 and N-cadherin orient the migration of multipolar neurons in the developing neocortex. Nat. Neurosci. 14, 697-703. doi: $10.1038 / \mathrm{nn} .2816$

Jossin, Y., and Goffinet, A. M. (2007). Reelin Signals through phosphatidylinositol 3-kinase and Akt to control cortical development and through mTor to regulate dendritic growth. Mol. Cell. Biol. 27, 7113-7124. doi: 10.1128/mcb. 00928-07

Jossin, Y., Gui, L., and Goffinet, A. M. (2007). Processing of Reelin by embryonic neurons is important for function in tissue but not in dissociated cultured neurons. J. Neurosci. 27, 4243-4252. doi: 10.1523/jneurosci.0023-07.2007

Jossin, Y., Ignatova, N., Hiesberger, T., Herz, J., Lambert de Rouvroit, C., and Goffinet, A. M. (2004). The central fragment of Reelin, generated by proteolytic processing in vivo, is critical to its function during cortical plate development. J. Neurosci. 24, 514-521. doi: 10.1523/jneurosci.3408-03.2004

Kim, M., Jeong, Y., and Chang, Y. C. (2015). Extracellular matrix protein reelin regulate dendritic spine density through CaMKII $\beta$. Neurosci. Lett. 599, 97-101. doi: 10.1016/j.neulet.2015.05.033

Kohno, T., Honda, T., Kubo, K., Nakano, Y., Tsuchiya, A., Murakami, T., et al. (2015). Importance of Reelin C-terminal region in the development and maintenance of the postnatal cerebral cortex and its regulation by specific proteolysis. J. Neurosci. 35, 4776-4787. doi: 10.1523/JNEUROSCI.4119-14. 2015

Koie, M., Okumura, K., Hisanaga, A., Kamei, T., Sasaki, K., Deng, M., et al. (2014). Cleavage within Reelin repeat 3 regulates the duration and range of the signaling activity of Reelin protein. J. Biol. Chem. 289, 12922-12930. doi: 10. 1074/jbc.M113.536326

Kojima, T., Nakajima, K., and Mikoshiba, K. (2000). The disabled 1 gene is disrupted by a replacement with L1 fragment in yotari mice. Brain Res. Mol. Brain Res. 75, 121-127. doi: 10.1016/S0169-328X(99)00313-7

Krstic, D., Rodriguez, M., and Knuesel, I. (2012). Regulated proteolytic processing of Reelin through interplay of tissue plasminogen activator (tPA), ADAMTS4, ADAMTS-5 and their modulators. PLoS One 7:e47793. doi: 10.1371/journal. pone. 0047793
Krueger, D. D., Howell, J. L., Hebert, B. F., Olausson, P., Taylor, J. R., and Nairn, A. C. (2006). Assessment of cognitive function in the heterozygous reeler mouse. Psychopharmacology (Berl) 189, 95-104. doi: 10.1007/s00213006-0530-0

Kubo, K., Mikoshiba, K., and Nakajima, K. (2002). Secreted Reelin molecules form homodimers. Neurosci. Res. 43, 381-388. doi: 10.1016/s0168-0102(02)00068-8

Kuo, G., Arnaud, L., Kronstad-O'Brien, P., and Cooper, J. A. (2005). Absence of Fyn and Src causes a reeler-like phenotype. J. Neurosci. 25, 8578-8586. doi: 10. 1523/jneurosci.1656-05.2005

Kupferman, J. V., Basu, J., Russo, M. J., Guevarra, J., Cheung, S. K., and Siegelbaum, S. A. (2014). Reelin signaling specifies the molecular identity of the pyramidal neuron distal dendritic compartment. Cell 158, 1335-1347. doi: 10. 1016/j.cell.2014.07.035

Lambert de Rouvroit, C., and Goffinet, A. M. (1998). The reeler mouse as a model of brain development. Adv. Anat. Embryol. Cell Biol. 150, 1-106. doi: 10. 1007/978-3-642-72257-8_1

Lane-Donovan, C., Philips, G. T., Wasser, C. R., Durakoglugil, M. S., Masiulis, I., Upadhaya, A., et al. (2015). Reelin protects against amyloid $\beta$ toxicity in vivo. Sci. Signal. 8:ra67. doi: 10.1126/scisignal.aaa6674

Lee, G. H., Chhangawala, Z., von Daake, S., Savas, J. N., Yates, J. R., III, Comoletti, D., et al. (2014). Reelin induces Erk1/2 signaling in cortical neurons through a non-canonical pathway. J. Biol. Chem. 289, 20307-20317. doi: 10. 1074/jbc.M114.576249

Lee, G. H., Kim, S. H., Homayouni, R., and D'Arcangelo, G. (2012). Dab2ip regulates neuronal migration and neurite outgrowth in the developing neocortex. PLoS One 7:e46592. doi: 10.1371/journal.pone. 0046592

MacLaurin, S. A., Krucker, T., and Fish, K. N. (2007). Hippocampal dendritic arbor growth in vitro: regulation by Reelin-Disabled-1 signaling. Brain Res. 1172, 1-9. doi: 10.1016/j.brainres.2007.07.035

Matsuki, T., Matthews, R. T., Cooper, J. A., van der Brug, M. P., Cookson, M. R., Hardy, J. A., et al. (2010). Reelin and stk 25 have opposing roles in neuronal polarization and dendritic Golgi deployment. Cell 143, 826-836. doi: 10.1016/j. cell.2010.10.029

Meseke, M., Rosenberger, G., and Förster, E. (2013). Reelin and the Cdc42/Rac1 guanine nucleotide exchange factor $\alpha$ PIX/Arhgef6 promote dendritic Golgi translocation in hippocampal neurons. Eur. J. Neurosci. 37, 1404-1412. doi: 10. 1111/ejn.12153

Miyata, T., Nakajima, K., Mikoshiba, K., and Ogawa, M. (1997). Regulation of Purkinje cell alignment by Reelin as revealed with CR-50 antibody. J. Neurosci. 17, 3599-3609.

Nakano, Y., Kohno, T., Hibi, T., Kohno, S., Baba, A., Mikoshiba, K., et al. (2007). The extremely conserved C-terminal region of Reelin is not necessary for secretion but is required for efficient activation of downstream signaling. J. Biol. Chem. 282, 20544-20552. doi: 10.1074/jbc.m702300200

Niu, S., Renfro, A., Quattrocchi, C. C., Sheldon, M., and D'Arcangelo, G. (2004). Reelin promotes hippocampal dendrite development through the VLDLR/ApoER2-Dab1 pathway. Neuron 41, 71-84. doi: 10.1016/s08966273(03)00819-5

Niu, S., Yabut, O., and D'Arcangelo, G. (2008). The Reelin signaling pathway promotes dendritic spine development in hippocampal neurons. J. Neurosci. 28, 10339-10348. doi: 10.1523/JNEUROSCI.1917-08.2008

O’Dell, R. S., Cameron, D. A., Zipfel, W. R., and Olson, E. C. (2015). Reelin Prevents Apical Neurite Retraction during Terminal Translocation and Dendrite Initiation. J. Neurosci. 35, 10659-10674. doi: 10.1523/JNEUROSCI. 1629-15.2015

Ogawa, M., Miyata, T., Nakajima, K., Yagyu, K., Seike, M., Ikenaka, K., et al. (1995). The reeler gene-associated antigen on Cajal-Retzius neurons is a crucial molecule for laminar organization of cortical neurons. Neuron 14, 899-912. doi: 10.1016/0896-6273(95)90329-1

Park, T. J., and Curran, T. (2008). Crk and Crk-like play essential overlapping roles downstream of disabled-1 in the Reelin pathway. J. Neurosci. 28, 13551-13562. doi: 10.1523/JNEUROSCI.4323-08.2008

Pesold, C., Impagnatiello, F., Pisu, M. G., Uzunov, D. P., Costa, E., Guidotti, A., et al. (1998). Reelin is preferentially expressed in neurons synthesizing g-aminobutyric acid in cortex and hippocampus of adult rats. Proc. Natl. Acad. Sci. U S A 95, 3221-3226. doi: 10.1073/pnas.95. 6.3221 
Pramatarova, A., Ochalski, P. G., Chen, K., Gropman, A., Myers, S., Min, K. T., et al. (2003). Nck beta interacts with tyrosine-phosphorylated disabled 1 and redistributes in Reelin-stimulated neurons. Mol. Cell. Biol. 23, 7210-7221. doi: $10.1128 / \mathrm{mcb} .23 .20 .7210-7221.2003$

Pujadas, L., Gruart, A., Bosch, C., Delgado, L., Teixeira, C. M., Rossi, D., et al. (2010). Reelin regulates postnatal neurogenesis and enhances spine hypertrophy and long-term potentiation. J. Neurosci. 30, 4636-4649. doi: 10. 1523/JNEUROSCI.5284-09.2010

Pujadas, L., Rossi, D., Andres, R., Teixeira, C. M., Serra-Vidal, B., Parcerisas, A., et al. (2014). Reelin delays amyloid-beta fibril formation and rescues cognitive deficits in a model of Alzheimer's disease. Nat. Commun. 5:3443. doi: 10. 1038/ncomms4443

Qiao, S., Kim, S. H., Heck, D., Goldowitz, D., LeDoux, M. S., and Homayouni, R. (2013). Dab2IP GTPase activating protein regulates dendrite development and synapse number in cerebellum. PLoS One 8:e53635. doi: 10.1371/journal.pone. 0053635

Qiu, S., Korwek, K. M., Pratt-Davis, A. R., Peters, M., Bergman, M. Y., and Weeber, E. J. (2006). Cognitive disruption and altered hippocampus synaptic function in Reelin haploinsufficient mice. Neurobiol. Learn. Mem. 85, 228-242. doi: 10.1016/j.nlm.2005.11.001

Sanada, K., Gupta, A., and Tsai, L. H. (2004). Disabled-1-regulated adhesion of migrating neurons to radial glial fiber contributes to neuronal positioning during early corticogenesis. Neuron 42, 197-211. doi: 10.1016/S08966273(04)00222-3

Sato, Y., Kobayashi, D., Kohno, T., Kidani, Y., Prox, J., Becker-Pauly, C., et al. (2016). Determination of cleavage site of Reelin between its sixth and seventh repeat and contribution of meprin metalloproteases to the cleavage. J. Biochem. 159, 305-312. doi: 10.1093/jb/mvv102

Sekine, K., Kawauchi, T., Kubo, K., Honda, T., Herz, J., Hattori, M., et al. (2012). Reelin controls neuronal positioning by promoting cell-matrix adhesion via inside-out activation of integrin $\alpha 5 \beta 1$. Neuron 76, 353-369. doi: 10.1016/j. neuron.2012.07.020

Sheldon, M., Rice, D. S., D’Arcangelo, G., Yoneshima, H., Nakajima, K., Mikoshiba, K., et al. (1997). Scrambler and yotari disrupt the disabled gene and produce a reeler-like phenotype in mice. Nature 389, 730-733. doi: 10. 1038/39601

Strasser, V., Fasching, D., Hauser, C., Mayer, H., Bock, H. H., Hiesberger, T., et al. (2004). Receptor clustering is involved in Reelin signaling. Mol. Cell. Biol. 24, 1378-1386. doi: 10.1128/mcb.24.3.1378-1386.2004

Suetsugu, S., Tezuka, T., Morimura, T., Hattori, M., Mikoshiba, K., Yamamoto, T., et al. (2004). Regulation of actin cytoskeleton by mDab1 through N-WASP and ubiquitination of mDab1. Biochem. J. 384, 1-8. doi: 10.1042/bj20041103

Telese, F., Ma, Q., Perez, P. M., Notani, D., Oh, S., Li, W., et al. (2015). LRP8-reelin-regulated neuronal enhancer signature underlying learning and memory formation. Neuron 86, 696-710. doi: 10.1016/j.neuron. 2015.03.033

Trommsdorff, M., Gotthardt, M., Hiesberger, T., Shelton, J., Stockinger, W., Nimpf, J., et al. (1999). Reeler/Disabled-like disruption of neuronal migration in knockout mice lacking the VLDL receptor and ApoE receptor 2. Cell 97, 689-701. doi: 10.1016/s0092-8674(00)80782-5

Trotter, J., Lee, G. H., Kazdoba, T. M., Crowell, B., Domogauer, J., Mahoney, H. M., et al. (2013). Dabl is required for synaptic plasticity and associative learning. J. Neurosci. 33, 15652-15668. doi: 10.1523/JNEUROSCI.2010-13.2013

Utsunomiya-Tate, N., Kubo, K., Tate, S., Kainosho, M., Katayama, E., Nakajima, K., et al. (2000). Reelin molecules assemble together to form a large protein complex, which is inhibited by the function-blocking CR-50 antibody. Proc. Natl. Acad. Sci. U S A 97, 9729-9734. doi: 10.1073/pnas.160272497

Ventruti, A., Kazdoba, T. M., Niu, S., and D'Arcangelo, G. (2011). Reelin deficiency causes specific defects in the molecular composition of the synapses in the adult brain. Neuroscience 189, 32-42. doi: 10.1016/j.neuroscience.2011. 05.050

Ware, M. L., Fox, J. W., Gonzáles, J. L., Davis, N. M., Lambert de Rouvroit, C., Russo, C. J., et al. (1997). Aberrant splicing of a mouse disabled homolog, mdab1, in the scrambler mouse. Neuron 19, 239-249. doi: 10.1016/s08966273(00)80936-8

Weeber, E. J., Beffert, U., Jones, C., Christian, J. M., Forster, E., Sweatt, J. D., et al. (2002). Reelin and ApoE receptors cooperate to enhance hippocampal synaptic plasticity and learning. J. Biol. Chem. 277, 39944-39952. doi: 10. 1074/jbc.m205147200

Wynshaw-Boris, A., and Gambello, M. J. (2001). LIS1 and dynein motor function in neuronal migration and development. Genes Dev. 15, 639-651. doi: 10. $1101 /$ gad. 886801

Yasui, N., Nogi, T., Kitao, T., Nakano, Y., Hattori, M., and Takagi, J. (2007). Structure of a receptor-binding fragment of reelin and mutational analysis reveal a recognition mechanism similar to endocytic receptors. Proc. Natl. Acad. Sci. U S A 104, 9988-9993. doi: 10.1073/pnas.0700438104

Yasui, N., Nogi, T., and Takagi, J. (2010). Structural basis for specific recognition of reelin by its receptors. Structure 18, 320-331. doi: 10.1016/j.str.2010.01.010

Yoneshima, H., Nagata, E., Matsumoto, M., Yamada, M., Nakajima, K., Miyata, T., et al. (1997). A novel neurological mutation of mouse, yotari, which exhibits reeler-like phenotype but expresses reelin. Neurosci. Res. 29, 217-223. doi: 10. 1016/s0168-0102(97)00088-6

Zhang, G., Assadi, A. H., McNeil, R. S., Beffert, U., Wynshaw-Boris, A., Herz, J., et al. (2007). The PAFAH1b complex interacts with the reelin receptor VLDLR. PLoS One 2:e252. doi: 10.1371/journal.pone.0000252

Conflict of Interest Statement: The authors declare that the research was conducted in the absence of any commercial or financial relationships that could be construed as a potential conflict of interest.

Copyright $\odot 2016$ Lee and D'Arcangelo. This is an open-access article distributed under the terms of the Creative Commons Attribution License (CC BY). The use, distribution and reproduction in other forums is permitted, provided the original author(s) or licensor are credited and that the original publication in this journal is cited, in accordance with accepted academic practice. No use, distribution or reproduction is permitted which does not comply with these terms. 